\title{
Exploration on the Social Value of Information Technology Curriculum under the Background of Post Figurative Culture
}

\author{
Zhang Zhigang ${ }^{1, a}$ \\ ${ }^{1}$ Baicheng Normal College, Media Institute, Baicheng, Jilin \\ a zhangzhigang3249@163.com
}

Keywords: Culture; Information Technology; Sociality

\begin{abstract}
The influence of post figurative culture is more obvious in the information society. The information of basic education in China from the hardware construction to start, gradually promote the software construction, the development of information technology education mode of the whole process of Western influence, Western civilization and eastern traditional culture jointly established the basic mode of information of education in our country, the social status of the contact information and the current information education is not enough close, students in information technology curriculum is located only in the field of IT cognition, instrumental features of information technology curriculum is extremely obvious, seriously curb the further development of information technology disciplines, influence the curriculum for students should first affect the lives of students, as an opportunity to influence students' ideas, eventually reshaping the thinking of students, obviously, the information technology curriculum in our country is lack of effective teaching in this aspect. In the context of post figurative culture, this paper probes into the social value of information technology curriculum, and expects to give full play to the teaching value of it courses.
\end{abstract}

\section{The Basic Characteristics of Post Figurative Culture in Education}

A. The Post Figurative Culture is a New Mode of Cultural Transmission Based on the Future

The transfer path is: the elder to the younger generation to learn. Young people in accordance with their first freedom spirit, they can in an unknown direction guide for the elderly. Post figurative culture originates from the coming of postindustrial society. The information revolution based on knowledge is the highlight of the postindustrial society.

B. Post Figurative Culture Advocates an Innovative Education for the Future

This innovative education not only requires students to learn general knowledge, but also requires students to learn how to deal with rapid change, how to think, decision making and problem solving, how to create their own insight and creativity. The changes of the times make the whole education environment change. The teaching of post figurative culture takes "innovation" as its mission, and the teaching at this time is a kind of bilateral activity that promotes the growth of teachers and students. Communication is the premise to realize the interaction between teachers and students, the teaching activity itself is not only a kind of practice activity, but also a process of information exchange. In the transmission mode of post figurative culture, information exchange is the center of teaching activities.

C. The Post Figurative Culture Provides Sufficient Time and Space for the Study

The innovation education based on the post figurative culture breaks the barrier between school education and no school education. The popularity of the network makes the transfer of information is no longer limited, teachers and students can be arranged in a relatively loose space and time to teach and learning activities, teaching tends to personalize and specialization.

D. The Post Figurative Culture Attaches Importance to the Mutual Learning between Teachers and Students, Emphasizing Democratic Equality

Pay attention to the interaction between teachers and students, will focus on communication; attention to the development of teachers and students, will create, update and adapt in teaching. Classroom activities are not only a process of teaching activities, but also the process of life and 
growth of teachers and students. It is an important life experience in the life of teachers and students. The concept of teaching includes teachers' teaching, students' learning and teachers' interactive teaching.

\section{The Basic Characteristics of the Information Society in Education}

\section{A. Information Replaces Knowledge}

The basic characteristics of information society can be summarized as: knowledge society, service society, public society. Information is meaningful data, knowledge is meaningful information. Information processing, applied to production, can be transformed into knowledge. To replace the traditional sense of the knowledge of the concept of information, means that our era is an era of knowledge explosion, the information is not completely transformed into knowledge, who can quickly obtain information, understand the information, processing information, grasps the initiative of social competition. It is clear that knowledge has become the primary capital of advanced economy.

B. The Change of the Relationship between Man and Man

Information has become the driving force of economic development, the power of social change, and changed the relationship between people. In the information society, the core of this new relationship is communication, to self-change the response to the various requirements of the reaction is the dialogue between people, and is no longer the kind of man and machine in the industrial society, this is the information society, knowledge economy society sign.

C. The Innovation of the Younger Generation Plays an Important Role in the Society

Special technology is the basis of power, education is a way to get power, along with the popularization of knowledge, more and more people are entering the knowledge class, and they have come to power through knowledge, so there are plans to make the management of society. However, the original structure of the social management system is gradually being eliminated by the network, the information society brought about by the network of heaven and earth to give full space to enjoy a wide range of democracy and freedom. Education is even more so, the emergence of virtual teaching has epoch-making significance. Virtual reality corresponds to the digital form. It is the embodiment of the virtual world in teaching, that is, to provide digital teaching space or digital learning environment.

\section{The Characteristics of the Learners under the Influence of Post Figurative Culture}

The status of information in the information society information is significantly enhanced, replace knowledge become the main content of school education in the new period, as meaningful data, diversity of information displayed and frontier is the existing traditional knowledge cannot match the information flexibility and innovation performance meet the needs of different learners' actual learning needs after all, but the information is not equivalent to the knowledge, knowledge is meaningful information, information from the rise to the knowledge in the process, the traditional teaching will play important functions of cultural inheritance, inheritance is the starting point of all educational activities, just to the starting point of teaching innovation provides the impetus, innovation is the basis of criticism and inheritance of traditional in the teaching, the older generation can assume the function of cultural heritage, but because of the amount of information increases rapidly with the consumption of the traditional knowledge update speed The degree of information lags far behind the growth rate between information and knowledge, information and knowledge is gradually transitional knowledge, the knowledge should be based on two aspects: one is to grasp the degree of traditional knowledge system, this is the older generation have the advantage, two is the access to information and understanding this is the younger generation, the advantage of one of the most important learning starting point is also learning the information society, based on different starting point, teachers and learners should form a learning community in the teaching, in the cultural heritage, learning to teacher learning, in the process of integration of information and traditional knowledge, teachers should fully reference learners willingness to learn. 


\section{The Cultural Characteristics and Social Characteristics of Information Technology Courses}

In terms of information technology curriculum, its culture is pluralistic orientation, the pluralistic orientation is based on future design, social development and social needs of the future of information technology curriculum is very important, is the development of the future development trend, this trend is inferred from the available information, is a kind of being formed obviously, the knowledge integration process of traditional knowledge, the integration in the information society is the inheritance and development of traditional culture, is to maximize the information resources on the basis of common sharing, one yuan is the core element is multi-platform, respect for diversity of the total information increase is an inexhaustible motive force for the information society forward, prominent the performance of this culture is "change", the connotation of culture in continuous expansion, the extension of the culture in the unceasing enlargement, this background, According to the traditional teaching methods, any learner can effectively complete the information society of the learning task, especially the information technology teaching, application software for study, rapid increase of constantly upgrading its content and complex software version brings knowledge, is a learner to face this situation. And develop information literacy in software learning is emerging, technology is to serve people, different learners on the use of the software is not the same, learning needs are not the same, but in the process of cultivation of information literacy, but the use of these technologies is the learner's information ability in a practice in the information world, this ability should be of universal significance.

The social characteristics of information technology curriculum is the digital world of life, in the digital world is an important means to verify the viability of the learning ability, the digital world is to learn the maximum mapping of the real life situation, in time and space to maximize the expansion of learning the sensory dimension, the social characteristics of information technical courses must be rooted in certain information situation, situational teaching should be in the information technology curriculum teaching should play an important role.

\section{Multiple Representations of the Social Value of Information Technology Curriculum}

The social characteristics of information technology curriculum is the digital world of life, in the digital world is an important means to verify the viability of the learning ability, the digital world is to learn the maximum mapping of the real life situation, in time and space to maximize the expansion of learning the sensory dimension, the social characteristics of information technical courses must be rooted in certain information situation, situational teaching should be in the information technology curriculum teaching should play an important role.

\section{A. The Formation of Learning Community}

The information society determines the information technology teachers must from "preaching" the altar go down, to students, and students form a learning community. In the learning community, teachers should not only to look at the assimilation of various views and opinions on the students' knowledge and theory in the learning process, but also should take an attitude of accommodation and learning to accept different opinions and views, and students teach and learn from each other, in the development of the students and develop their own, the concept of lifelong learning to be implemented in the learning community, learning community is a specific form of information technology curriculum of social value, has a very important guiding significance in practice.

\section{B. Innovation and Development on the Basis of Cultural Heritage}

The information society presents the social value of post figurative culture characteristics determine the course of information technology for innovation, innovation is the source of information, the information society is the driving force for the development of the cultural heritage on the basis of national innovation is to carry forward the spirit of the premise, is the basic principle of innovation.

\section{Digital Viability}

When people use computers, multimedia, Internet and other digital elements to reconstruct our living environment, digital survival and human thinking has become the common theme that people 
must experience. People's understanding of information and skills become the basic ability of the information society, in terms of information technology curriculum, emphasizing the ability to survive will enable us to attach importance to the technology behind the law of survival, the information technology curriculum taught us the information society is precisely the law of survival, rather than industrial society technology.

\section{Digital Learning}

Digital learning has three elements. First, the digital learning environment, also known as information technology learning environment. It has the characteristics of multimedia information display, information transmission network, and intelligent information processing and virtual teaching environment. It includes facilities, resources, platforms, communications and tools. Two is the digital learning resources. It refers to the digital media which can be run on the multimedia computer or network environment. Including digital video, digital audio, multimedia software, CD-ROM, web site, e-mail, online learning management system, computer simulation, online discussion, data files and databases. Digital learning resources is the key to digital learning. Three is the digital learning. The use of digital platforms and resources, teachers and students to carry out consultations between the discussion, cooperative learning, and through the collection and utilization of resources, knowledge, knowledge discovery, knowledge creation and knowledge presentation modes of learning, with the use of resources, self-discovery, negotiation and cooperation and create practice in several ways. In general, it is necessary to design and teach information technology courses in the field of digital learning, which is an important way to reflect the social value of information technology curriculum.

E. The Cultivation of Information Literacy Has Become the Most Common Quality of Citizens in the Information Society

The information technology curriculum in general teaching goal directly reflects the social value of the curriculum of information technology, information literacy will be the organic combination of information science, information technology, social culture, information society and many other factors, from the perspective of citizen information social basic values courses. Information literacy is the sum of the knowledge, ability, and emotion that people have the ability to identify, process, use, innovate and manage information. Includes information knowledge, information ability and information emotion, information knowledge is the people in the use of information technology tools, expand the channels of information dissemination, the sum of knowledge and experience accumulated in the exchange of information to improve the efficiency, which constitute the basis of information literacy. The information ability is the individual psychological characteristic which the person must carry on the information activity, which is the core of information quality. Information emotion and consciousness involve people's attitude, emotion, consciousness and moral standard of information and information technology. Based on the cultivation of information literacy to design and explain the information technology curriculum, which is an important concept of the value of information society.

\section{Conclusion}

The implementation of information technology curriculum is not only the basis for teachers to effectively teach information technology courses. This knowledge and the development of students' basic skills, but mainly to develop a personalized, free learners. Teachers and students should be aware of their own identity and take part in the curriculum implementation with their different identities. At the same time, in the course of its implementation, other teachers, principals, parents, community members, curriculum experts, etc., are part of the cultural power sharing, and participate in the implementation of the curriculum in a special form.

\section{References}

[1] Qian Xusheng. The Construction of a New Relationship Between Teachers and Students Based on Cultural Power Sharing [J]. Education Research, 2010 (04); 
[2] Moore Michael G. introduction [A ] . Gibson, C.C et al. Distance Learners in Higher Education: Institutional Responses for Quality Outcomes [C] . Madison: Atwood Publishing. 1998.1-7.

[3] Yang Yang, Liu Jianguo. On the Social Attribute and Cultural Attribute of Information Technology Curriculum Theory[J]. Journal of Jilin Teachers College of Engineering and Technology,2014(09);

[4] Yu Huazhong. Tradition and Emerging Complement Each Other-A Study on the Teaching of Chinese Traditional Culture in the Course of Information Technology in Junior High School [J]. China Modern Education Technology Equipment, 2014(04).

[5] Wang Liang.Digital Resources Supermarket Push Personalized Resources[J]. The Modern Education Technology,2011(01);

[6] Zheng Jun.Take Network Information Service of Push and Pull Mode[J]. Modern Library and Information Technology,2002(05). 